\title{
Practical management of new oral anticoagulants after total hip or total knee arthroplasty
}

\author{
W. Klauser • M. Dütsch
}

Received: 31 October 2013/Accepted: 4 November 2013/Published online: 19 November 2013

(c) The Author(s) 2013. This article is published with open access at Springerlink.com

\begin{abstract}
Within the past 5 years, the oral anticoagulants rivaroxaban, apixaban, and dabigatran etexilate have been approved for the prevention of venous thromboembolism in adult patients after elective hip or knee arthroplasty in the European Union and many other countries worldwide. These agents differ from the previously available anticoagulants because they selectively and directly inhibit a single factor in the coagulation cascade-rivaroxaban and apixaban inhibit Factor Xa, and dabigatran inhibits Factor IIa (thrombin)—-potentially enhancing the predictability of their anticoagulant effect. Currently, although some guidelines provide recommendations for the use of rivaroxaban, dabigatran etexilate, and apixaban in clinical practice, there are still questions regarding the optimal practical management of patients receiving these agents. This article briefly reviews the practical limitations associated with conventional anticoagulants, discusses potential issues with the practical management of the newer oral anticoagulants, and provides clinical experience from a single institution where rivaroxaban and dabigatran etexilate have been used within their approved indications.
\end{abstract}

Keywords Oral anticoagulants - Deep vein thrombosis · Hip and knee arthroplasty

W. Klauser $(\square)$

Orthopaedic Department, Helios ENDO Klinik Hamburg, Holstenstraße 2, 22767 Hamburg, Germany

e-mail: wolfgang.klauser@helios-kliniken.de

M. Dütsch

Helios ENDO Klinik, Hamburg, Germany

\section{Introduction}

Venous thromboembolism (VTE), which comprises deep vein thrombosis and pulmonary embolism, is a potentially life-threatening complication of major orthopedic surgery. Unfractionated heparin (UFH), low molecular weight heparins (LMWHs), and vitamin K antagonists (VKAs) have been used for the prevention of VTE after major orthopedic surgery for more than 20 years $[1,20]$. In Europe, the LMWH enoxaparin has become the standard of care in this indication. The practical management of these anticoagulants is well established, and their limitations have been well documented; these include parenteral administration in the case of UFH and the LMWHs, and unpredictable pharmacology in the case of VKAs [3, 33].

In 2005, the synthetic pentasaccharide fondaparinux was approved in the European Union (EU) for the prevention of VTE after major orthopedic surgery. Fondaparinux indirectly inhibits Factor Xa, an enzyme of the coagulation cascade involved in the generation of thrombin, via the cofactor antithrombin [66]. The mechanism of action of fondaparinux differs from conventional anticoagulants in that it selectively targets a single factor in the coagulation cascade (Fig. 1), increasing the predictability of its anticoagulant effect in comparison with UFH and the VKAs [13]. However, use of fondaparinux is still limited by the fact that it is administered by subcutaneous injection. In 2008, two direct oral anticoagulants were approved in the EU for the prevention of VTE in adult patients after elective hip or knee arthroplasty: the direct Factor Xa inhibitor rivaroxaban and the direct thrombin inhibitor dabigatran (the active form of dabigatran etexilate). In 2011, a third oral anticoagulant-the direct Factor Xa inhibitor apixaban-was approved in the same indication. Like fondaparinux, these three agents selectively inhibit a single 


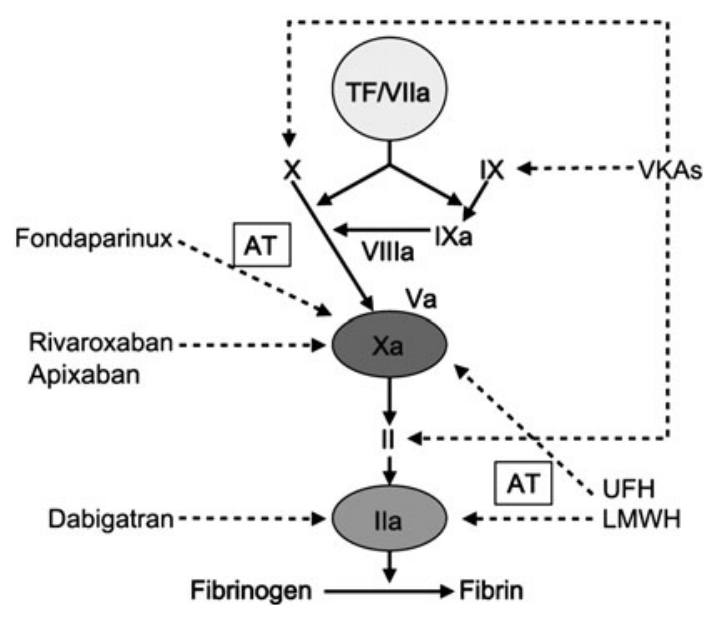

Fig. 1 The coagulation cascade and anticoagulant targets. $a$ activated, $A T$ antithrombin, $L M W H$ low molecular weight heparin, $T F$ tissue factor, $U F H$ unfractionated heparin, $V K A$ vitamin $\mathrm{K}$ antagonist

target in the coagulation cascade, but unlike fondaparinux, they are not dependent on binding to antithrombin for their activity (Fig. 1) [52, 61, 69].

The internationally recognized American College of Chest Physicians (ACCP) guidelines for the prevention of VTE recommend anticoagulation with LMWH, fondaparinux, dabigatran, apixaban, rivaroxaban, low-dose UFH, or a VKA after total hip arthroplasty (THA) or total knee arthroplasty (TKA) [20]. Thromboprophylaxis is recommended for a minimum of 10-14 days after THA or TKA; however, it is suggested that extending treatment for up to 35 days may provide additional benefit [20]. The UK National Institute for Health and Clinical Excellence (NICE) and the Scottish Medicines Consortium recommend the use of rivaroxaban, dabigatran, or apixaban within their marketing authorization, as alternatives to established agents for the prevention of VTE after elective THA or TKA [47-49, 57-59]. The Association of the Scientific Medical Societies in Germany also makes recommendations for dabigatran and rivaroxaban in this indication [4].

Rivaroxaban and dabigatran have now been available for the prevention of VTE after elective hip or knee arthroplasty for more than 4 years in the EU, while apixaban was approved for the same indication in May 2011. This review focuses on the clinical experience with rivaroxaban and dabigatran in a single institution and discusses potential issues surrounding the practical management of these agents.

\section{Established anticoagulants: practical management issues}

As a result of their long-established use, conventional anticoagulants are well trusted. However, their effective management necessitates a number of practical considerations. In Europe, LMWHs are recommended to be given preoperatively [20], which prevents same-day hospital admission for elective surgery, and can complicate decisions related to the method of anesthesia. In Europe, UFH is usually administered subcutaneously at a low dose; LMWHs and fondaparinux are also administered subcutaneously. This can make their long-term use inconvenient, particularly after hospital discharge. If it is necessary to administer high-dose UFH intravenously, the variable anticoagulant response that patients have to UFH necessitates dose adjustment and routine coagulation monitoring [33]. Furthermore, use of UFH is known to have a risk of heparin-induced thrombocytopenia [28]. Because of these limitations, the use of UFH has largely been replaced by LMWHs, although these drugs have their own limitations [28].

In Germany, it is considered good clinical practice to administer LMWH for a period of 28 days after THA or TKA. However, because the median length of hospital stay for THA or TKA outside the USA is 10 days [24], patients will often be discharged after surgery with injections that require self-administration; in the USA, the median length of hospital stay is even shorter ( 3 days after THA and 4 days after TKA) [24]. Many patients do not like selfinjecting, and others, especially elderly patients, may require assistance with injections. A family member may need to be trained to give the injections, or nurse visits may be necessary. As a result, many patients stop taking LMWH when they have left the hospital, placing themselves at increased risk of VTE. In an observational study conducted in six general hospitals and six rehabilitation centers in Germany, $71.9 \%$ of 178 patients said they would prefer oral rather than subcutaneous administration of VTE prophylaxis. Furthermore, a time saving of $46.13 \mathrm{~s}$ was observed in tablet preparation and administration compared with syringe preparation and administration [50].

When parenteral thromboprophylaxis is used at home, there can be self-administration issues. In telephone interviews conducted in the Netherlands in 687 patients who had undergone THA or TKA, a total of $511(74.4 \%)$ patients indicated that they used parenteral thromboprophylaxis at home. However, $48.8 \%$ of these patients reported administration problems, including pain, bruising, and itching. Home-care visits for parenteral administration problems were required by $9.9 \%$ (95\% confidence interval 6.4-13.4) and $9.6 \%$ (95\% confidence interval 5.8-13.4) of THA and TKA patients, respectively. Approximately $60 \%$ of all THA or TKA patients said they would prefer oral rather than parenteral thromboprophylaxis [11].

LMWHs are predominantly excreted renally, and in patients with impaired renal function, accumulation can 
occur, potentially increasing the risk of bleeding. Renal clearance is also the primary mode of elimination for fondaparinux [28]. In the Global Orthopaedic Registry (GLORY), the median age of patients undergoing THA or TKA was over 65 years [24]. Because renal function is known to decrease with age [30], the use and/or dose of LMWHs or fondaparinux should be considered carefully in this patient population. The ACCP guidelines recommend that in patients with renal impairment, the use of anticoagulants that accumulate should be avoided. Alternatively, a lower drug dose should be used, or drug levels and anticoagulant effect should be monitored [29].

VKAs have the advantage of being administered orally. However, because of other factors including genetics, considerable variability in dose response is observed among patients. For this reason, VKAs require regular coagulation monitoring and dose adjustments to ensure that patients stay within the therapeutic range [target international normalized ratio (INR) of 2.5 (range 2.0-3.0)] to reduce the risk of adverse events [1]. VKAs also have numerous food and drug interactions [1].

To minimize the risk of bleeding when anticoagulants are used together with epidural catheters, guidelines on the timing of catheter placement and withdrawal, in relation to dosing and peak plasma concentrations, are available for UFH, LMWHs, and VKAs [2, 34]. All patients receiving anticoagulants, including fondaparinux, with regional anesthesia and postoperative indwelling epidural catheters should be closely monitored for signs and symptoms of neurological impairment [2, 31, 34].

If an overdose occurs, UFH can be fully reversed using intravenous protamine sulfate. LMWHs do not have a specific antidote, although the effects can be partially reversed using protamine sulfate [28]. In the event of a VKA overdose, vitamin $\mathrm{K}$ administered orally or intravenously can be used, although its full effects can take up to $24 \mathrm{~h}$ [5]. For more rapid reversal, vitamin K may need to be supplemented with factor concentrates [3]. Fondaparinux has no known antidote [31].

\section{Management of direct oral anticoagulants}

\section{Timing of first dose}

The optimal timing of the first dose of an anticoagulant, in order to achieve a good balance between efficacy and safety, has always been a controversial issue. Evidence from a number of anticoagulant clinical trials of varying size and robustness has been reviewed [51]. The findings, predominantly from the trials of LMWHs, suggest that efficacy is not dependent on preoperative anticoagulant initiation and that $6 \mathrm{~h}$ is the threshold for early postoperative administration. When the first dose was initiated within $6 \mathrm{~h}$ postoperatively, the risk of major bleeding increased without improved efficacy, whereas initiation $6 \mathrm{~h}$ postoperatively was effective but not associated with an increased risk of major bleeding. However, initiation 12-24 h postoperatively could be less effective than initiation $6 \mathrm{~h}$ postoperatively [51].

Unlike LMWHs, rivaroxaban, apixaban, and dabigatran are initiated postoperatively $[7,10,12,20]$, allowing the convenience of hospital admission on the day of surgery. For the prevention of VTE after elective hip or knee arthroplasty, rivaroxaban $10 \mathrm{mg}$ is administered once daily as a single tablet. It is recommended that the first dose of rivaroxaban is administered $6-10 \mathrm{~h}$ postoperatively if adequate hemostasis has been established [7]. Apixaban is initiated $12-24 \mathrm{~h}$ after surgery at a dose of $2.5 \mathrm{mg}$ twice daily. Initiation within this time window is at the physician's discretion, depending on the need to balance the benefit of earlier VTE prophylaxis with the risk of postoperative bleeding [12]. Dabigatran is administered as a once-daily $220 \mathrm{mg}$ dose, taken as two capsules. The recommendation is that the first dose is administered $1-4 \mathrm{~h}$ after surgery as a half-dose (110 mg), continuing with two capsules once daily thereafter. If adequate hemostasis is not achieved, initiation of therapy should be delayed [10]. All patients are monitored intensely the night after surgery to check blood pressure and infusions. Therefore, if the first dose of oral anticoagulant is due during the night, dosing should not be delayed.

In our clinic, patients receiving general anesthesia during THA or TKA are administered the first dose of rivaroxaban $8-10 \mathrm{~h}$ postoperatively. In patients receiving regional anesthesia with an epidural catheter, the first dose of rivaroxaban is administered after the same postoperative time period. In the case of dabigatran, the first dose is administered 4-6 h postoperatively after general anesthesia. In patients receiving regional anesthesia with an epidural catheter, dabigatran is started after removal of the catheter.

\section{Vomiting}

One consideration when using oral rather than parenteral anticoagulants is the possibility of postoperative vomiting and the impact this may have on the effectiveness of the drug. A number of different factors could increase the risk of postoperative vomiting, including certain anesthetics, perioperative use of analgesics such as opioids, intense preoperative anxiety, or a history of migraine [27]. Rivaroxaban, dabigatran, and apixaban all have a fast onset of action. Rivaroxaban reaches peak plasma concentrations between 2 and $4 \mathrm{~h}$ after administration [7] and apixaban between 3 and $4 \mathrm{~h}$ after administration [12]. Dabigatran 
reaches peak plasma concentrations within $2 \mathrm{~h}$ of administration [10]. A fast onset of action is an advantage for an oral anticoagulant because the period when postoperative vomiting might be considered to be an issue, i.e., before the drug is absorbed, is relatively short. If a patient vomits more than $4 \mathrm{~h}$ after rivaroxaban or apixaban administration, or more than $2 \mathrm{~h}$ after dabigatran administration, no additional anticoagulation should be necessary. In clinical practice, if a patient receiving rivaroxaban or apixaban vomits within $4 \mathrm{~h}$ and the tablet is seen in the vomit, the dose is taken again if possible. If it is not clear whether the tablet has been regurgitated or not, the next tablet of rivaroxaban is taken $24 \mathrm{~h}$ after the last tablet intake. A similar procedure is followed if vomiting occurs soon after administration of dabigatran. Given its twice-daily dosing, the next apixaban tablet is taken $12 \mathrm{~h}$ after the last tablet intake. Nausea and vomiting can be managed with the use of antiemetics and antinauseants as required.

In our clinic, nausea and vomiting have not so far proved an issue when using the newer oral anticoagulants. If vomiting occurs, it is usually within the first $4 \mathrm{~h}$ after surgery, before administration of the first dose, or the following morning when the patient is mobilized for the first time. In the latter case, the first dose has been administered many hours previously, and the next dose is administered at the normal time.

\section{Concomitant medications}

As previously highlighted, patients undergoing THA or TKA are often elderly and may already be taking one or more medications. In addition, nonsteroidal anti-inflammatory drugs and acetylsalicylic acid, which are known to affect bleeding risk, may be prescribed for pain relief after major orthopedic surgery [22, 23, 32]. It is, therefore, important that any direct oral anticoagulant does not interact with these drugs or other commonly used medications. Based on interaction studies, the recommendations for the use of rivaroxaban, apixaban, and dabigatran with other drugs are summarized in Table 1. Although it has been shown that these drugs do not have clinically relevant interactions with nonsteroidal anti-inflammatory drugs or acetylsalicylic acid [12, 15, 19, 36], because of the risk of hemorrhage, patients should always be observed closely for signs of bleeding when using these drugs concomitantly.

\section{Coagulation monitoring}

In clinical trials, rivaroxaban, apixaban, and dabigatran were found to have predictable pharmacokinetics and pharmacodynamics [26, 38-40, 63, 64]. Because of their predictable anticoagulant effects, none of these agents requires routine coagulation monitoring. However, although coagulation monitoring is not required, there may be circumstances in the clinic when it is useful to determine the pharmacodynamic activity of these agents, for example, in the event of an overdose or during a hemostatic emergency. Several clotting assays have been evaluated for this purpose $[21,56]$. There is evidence that the INR, specifically designed for monitoring VKAs, is not suitable for monitoring rivaroxaban [60]. Prothrombin time (PT) assays calibrated to rivaroxaban concentrations may be useful to qualitatively assess the plasma levels of rivaroxaban if required, but results should be expressed as rivaroxaban concentration $(\mathrm{ng} / \mathrm{mL})$ and a central PT reagent should be used to minimize variability [54]. An anti-Factor $\mathrm{Xa}$ chromogenic assay has also been shown to provide quantitative measurements of rivaroxaban plasma concentrations [55]. However, these assays are not yet routinely available. For apixaban, measuring inhibition of Factor Xa activity using an anti-Factor $\mathrm{Xa}$ assay gives a better indication of plasma apixaban concentrations compared with the PT test and was shown to detect apixaban even at low plasma concentrations [6, 8]. Options for measuring the anticoagulant activity of dabigatran include the ecarin clotting time assay, and the commercially available hemoclot thrombin inhibitor assay (HYPHEN BioMed, Andresy, France) developed by the manufacturers of dabigatran $[62,63]$.

\section{Antidote}

In the event of an overdose, or during a rapidly progressing hemostatic emergency, such as a gastrointestinal or intracranial bleeding event, strategies for the reversal of the anticoagulant effect must be considered. Like LMWHs and fondaparinux, none of the direct oral anticoagulants has specific antidotes that can fully reverse their effects. However, in clinical practice, specific reversal of anticoagulants with relatively short half-lives, such as rivaroxaban, apixaban, and dabigatran, is not usually necessary. Rivaroxaban has a mean terminal half-life of 5-9 h in young individuals and 11-13 $\mathrm{h}$ in the elderly [7]; dabigatran has a mean terminal half-life of $12-14 \mathrm{~h}$ in healthy young individuals and $11 \mathrm{~h}$ in healthy elderly individuals [10]. The mean terminal half-life of apixaban is approximately $12 \mathrm{~h}$ [12].

In the event of an overdose, or in a bleeding emergency, a number of steps can be taken to reverse the effects of rivaroxaban. Activated charcoal can be used to reduce absorption. If bleeding occurs, discontinuation or delay of the next dose is recommended. If bleeding continues, an appropriate symptomatic treatment, such as blood product or component transfusion, should be considered. Administration of a specific procoagulant reversal agent, such as prothrombin complex concentrate (PCC), activated PCC 
Table 1 Interaction of comedications with rivaroxaban, dabigatran, and apixaban

\begin{tabular}{|c|c|c|}
\hline Anticoagulant & $\begin{array}{l}\text { Interaction/ } \\
\text { recommendation }\end{array}$ & Medication \\
\hline \multirow[t]{14}{*}{ Rivaroxaban } & \multirow[t]{8}{*}{$\begin{array}{l}\text { No clinically relevant } \\
\text { interaction }\end{array}$} & $\begin{array}{l}\text { Platelet aggregation inhibitors, } \\
\text { including acetylsalicylic acid } \\
{[15,36]}\end{array}$ \\
\hline & & $\begin{array}{l}\text { Nonsteroidal anti-inflammatory } \\
\text { drugs [15] }\end{array}$ \\
\hline & & Naproxen [7] \\
\hline & & Enoxaparin [7] \\
\hline & & Digoxin [7] \\
\hline & & Atorvastatin [7] \\
\hline & & Ranitidine [41] \\
\hline & & Clopidogrel [37] \\
\hline & \multirow[t]{2}{*}{ Use with caution [7] } & Fluconazole \\
\hline & & Strong CYP3A4 inducers \\
\hline & \multirow[t]{4}{*}{ Not recommended [7] } & Systemic azole antimycotics \\
\hline & & HIV protease inhibitors \\
\hline & & $\begin{array}{l}\text { Strong inhibitors of both } \\
\text { CYP3A4 and P-gp }\end{array}$ \\
\hline & & Dronedarone \\
\hline \multirow[t]{20}{*}{ Dabigatran } & \multirow{5}{*}{$\begin{array}{l}\text { No clinically relevant } \\
\text { interaction }\end{array}$} & Acetylsalicylic acid [19] \\
\hline & & $\begin{array}{l}\text { Nonsteroidal anti-inflammatory } \\
\text { drugs [19] }\end{array}$ \\
\hline & & Diclofenac [10] \\
\hline & & Digoxin [10] \\
\hline & & Atorvastatin [10] \\
\hline & $\begin{array}{l}\text { Dose reduction } \\
\text { recommended [10] }\end{array}$ & Amiodarone \\
\hline & \multirow[t]{2}{*}{ Use with caution [10] } & $\begin{array}{l}\text { Strong P-gp inhibitors, e.g., } \\
\text { verapamil or clarithromycin }\end{array}$ \\
\hline & & Quinidine \\
\hline & \multirow[t]{12}{*}{ Not recommended [10] } & $\begin{array}{l}\text { Potent P-gp inducers, e.g., } \\
\text { rifampicin }\end{array}$ \\
\hline & & $\begin{array}{l}\text { Unfractionated heparins and } \\
\text { heparin derivatives }\end{array}$ \\
\hline & & Low molecular weight heparins \\
\hline & & Fondaparinux \\
\hline & & Desirudin \\
\hline & & Thrombolytic agents \\
\hline & & GPIIb/IIIa receptor antagonists \\
\hline & & Clopidogrel \\
\hline & & Ticlopidine \\
\hline & & Dextran \\
\hline & & Sulfinpyrazone \\
\hline & & Vitamin $\mathrm{K}$ antagonists \\
\hline
\end{tabular}

(aPCC), or recombinant Factor VIIa, should be considered if previous measures are unsuccessful; however, there is limited clinical experience with these products in patients receiving rivaroxaban [7]. Both aPCC (FEIBA ${ }^{\circledR}$ Baxter AG, Vienna, Austria) and PCC (Kanokad ${ }^{\circledR}$, Courtaboeuf, France; Cofact, Sanquin Blood Supply, Amsterdam, the Netherlands) have shown potential for the reversal of
Table 1 continued

\begin{tabular}{|c|c|c|}
\hline Anticoagulant & $\begin{array}{l}\text { Interaction/ } \\
\text { recommendation }\end{array}$ & Medication \\
\hline \multirow[t]{15}{*}{ Apixaban } & $\begin{array}{l}\text { No clinically relevant } \\
\text { interaction }\end{array}$ & $\begin{array}{l}\text { Acetylsalicylic acid [12] } \\
\text { Digoxin [25] } \\
\text { Inhibitors or substrates of CYP } \\
\text { enzymes [68] } \\
\text { Naproxen [12] } \\
\text { Atenolol [12] } \\
\text { Famotidine [12] }\end{array}$ \\
\hline & Use with caution [12] & $\begin{array}{l}\text { Strong inducers of both } \\
\text { CYP3A4 and P-gp, e.g., } \\
\text { rifampicin, phenytoin, } \\
\text { carbamazepine, phenobarbital } \\
\text { Nonsteroidal anti-inflammatory } \\
\text { drugs }\end{array}$ \\
\hline & \multirow[t]{13}{*}{ Not recommended [12] } & $\begin{array}{l}\text { Strong inhibitors of both } \\
\text { CYP3A4 and P-gp, e.g., } \\
\text { ketoconazole, ritonavir }\end{array}$ \\
\hline & & $\begin{array}{l}\text { Unfractionated heparins and } \\
\text { heparin derivatives }\end{array}$ \\
\hline & & Low molecular weight heparins \\
\hline & & Fondaparinux \\
\hline & & Desirudin \\
\hline & & Thrombolytic agents \\
\hline & & GPIIb/IIIa receptor antagonists \\
\hline & & Clopidogrel \\
\hline & & Dipyridamole \\
\hline & & Dextran \\
\hline & & Sulfinpyrazone \\
\hline & & Vitamin $\mathrm{K}$ antagonists \\
\hline & & Other oral anticoagulants \\
\hline
\end{tabular}

rivaroxaban in ex vivo studies in healthy volunteers, but further investigation is required $[14,46]$.

The use of oral activated charcoal has been shown to reduce apixaban exposure in healthy subjects [12]. If there are bleeding complications, treatment should be discontinued and bleeding treated using standard methods. As with rivaroxaban, treatment with recombinant Factor VIIa can be considered if bleeding cannot be controlled; however, there is currently no clinical experience with this treatment for patients receiving apixaban.

In the event of a dabigatran overdose, the following steps should be taken: Treatment should be discontinued and the source of bleeding investigated; because dabigatran is excreted predominantly by the renal route, adequate diuresis must be maintained; initiation of the appropriate treatment, for example, surgical hemostasis or the transfusion of fresh frozen plasma, should be considered. Dabigatran can be dialyzed, but the clinical utility of this approach has not been determined [10]. In an ex vivo 
study, PCC was unable to reverse the anticoagulant effect of dabigatran; however, particle reversal was achieved with recombinant Factor VIIa and aPCC [14, 46].

Use of catheters

A consideration when using any anticoagulant together with regional anesthesia or spinal/epidural puncture is the increased risk of epidural or spinal hematoma. A recommended management strategy to reduce the risk of hemorrhagic events associated with regional anesthesia in patients receiving newer anticoagulants has been proposed [53]. This strategy is based on the pharmacokinetic properties of the specific anticoagulant, including the time required to reach maximal concentration, the half-life, and the dose regimen (Fig. 2). It is recommended that epidural catheters should not be removed until at least two half-lives after the last injection of the anticoagulant [53].

Based on this proposal, and the pharmacokinetic profile of rivaroxaban, it is recommended that an epidural catheter should not be removed earlier than $18 \mathrm{~h}$ after the last administration of the drug. The next rivaroxaban dose should be administered no earlier than $6 \mathrm{~h}$ after the removal of the catheter, and if traumatic puncture occurs, rivaroxaban administration should be delayed for $24 \mathrm{~h}$ [7]. Epidural catheters should be removed at least $5 \mathrm{~h}$ before initiating apixaban treatment [12]. For patients with indwelling catheters, it is recommended that $20-30 \mathrm{~h}$ should elapse between the last dose of apixaban and catheter removal. The use of dabigatran is not recommended in anesthetized patients with postoperative indwelling epidural catheters. The first dose of dabigatran should be administered at least $2 \mathrm{~h}$ after the catheter is removed, and these patients should be observed frequently for neurological signs and symptoms [10].

\section{Adverse drug reactions}

Three phase III trials compared rivaroxaban $10 \mathrm{mg}$ once daily with the EU-approved dose of enoxaparin $(40 \mathrm{mg}$ once daily) for the prevention of VTE after THA (RECORD1 and RECORD2) or TKA (RECORD3). RECORD1 and RECORD3 were head-to-head drug regimen comparisons, whereas RECORD2 compared extended-duration rivaroxaban with short-duration enoxaparin followed by placebo [16, 35, 42]. A fourth trial compared rivaroxaban $10 \mathrm{mg}$ once daily with enoxaparin $30 \mathrm{mg}$ twice daily after TKA [67]. Treatment-emergent, drugrelated adverse events occurring in $1-10 \%$ of any treatment group in these four trials were nausea, postprocedural hemorrhage, fever, peripheral edema, and increase in transaminases [7].

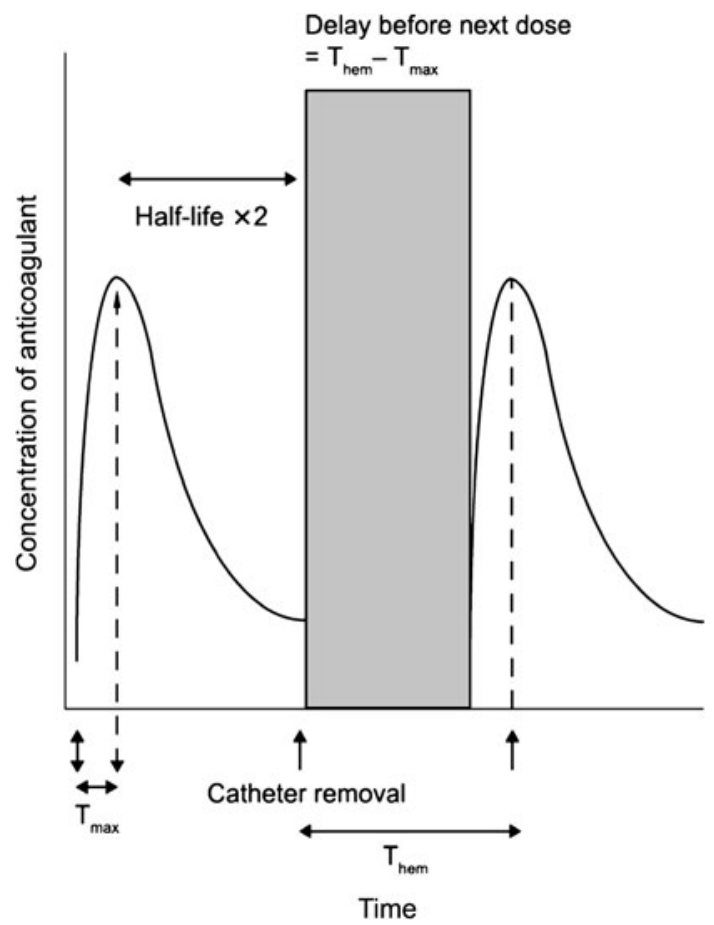

Fig. 2 Regional anesthesia management strategy. It is recommended that for a specific anticoagulant, catheter removal should occur after at least two half-lives have elapsed. The next dose of anticoagulant should not be administered until time to reach hemostasis $\left(T_{\text {hem }}\right)$ minus time to reach maximum plasma concentration $\left(T_{\max }\right)$ has elapsed $\left(T_{\text {hem }}-T_{\text {max }}\right)$

Two phase III studies compared apixaban $2.5 \mathrm{mg}$ twice daily with the EU-approved enoxaparin dose for the prevention of VTE after TKA (ADVANCE-2) or THA (ADVANCE-3) $[44,45]$. A third trial compared apixaban $2.5 \mathrm{mg}$ twice daily with enoxaparin $30 \mathrm{mg}$ twice daily after TKA [43]. Treatment-emergent adverse events that occurred in $1-10 \%$ of patients in clinical studies of apixaban were anemia, hemorrhage, nausea, and contusion [12].

Two phase III trials compared two doses of dabigatran (150 or $220 \mathrm{mg}$ once daily) with the EU-approved enoxaparin regimen for the prevention of VTE after THA (RENOVATE) or TKA (RE-MODEL) [17, 18]. Dabigatran was compared with enoxaparin $30 \mathrm{mg}$ twice daily in another phase III trial in TKA patients [65]. In these clinical trials, adverse events occurring in 1-10\% for both doses were anemia, hemoglobin decrease, epistaxis, gastrointestinal hemorrhage, abdominal pain, diarrhea, dyspepsia, and nausea [10].

In clinical practice in this institution, serious side effects have not been observed with rivaroxaban or dabigatran, although elevated transaminases and gamma-glutamyl transpeptidases leading to drug discontinuation have been observed more frequently with dabigatran. Anecdotally, in the wider orthopedic community, these direct oral 
anticoagulants have sometimes been associated with higher rates of postoperative effusions or bleeding compared with LMWH. It has been routine clinical practice to administer LMWH preoperatively, and in some cases, this practice has continued even after the introduction of the direct oral anticoagulants. The omission of preoperative LMWH resulted in a substantial decrease in these side effects. This highlights the importance of education for surgeons and anesthetists about how these drugs work and the potential implications of mismanagement.

\section{Contraindications}

As with all drugs, the direct oral anticoagulants are contraindicated for use in certain patient groups. Rivaroxaban, dabigatran, and apixaban are contraindicated in patients who are hypersensitive to the active substances or to any of the excipients; have clinically significant active bleeding; have lesions or a condition that puts them at significant risk of major bleeding; or are receiving concomitant treatment with any other anticoagulant [7, 10, 12]. Apixaban and rivaroxaban are also contraindicated in patients with hepatic disease associated with coagulopathy and risk of clinically relevant bleeding, and these agents should not be used in patients who are pregnant or breast-feeding [7, 12]. Dabigatran is also contraindicated in patients who have severe renal impairment (creatinine clearance $<30 \mathrm{~mL} / \mathrm{min}$ ); have hepatic impairment or liver disease expected to have any impact on survival; have prosthetic heart valves requiring anticoagulant treatment; or are receiving concomitant treatment with strong P-glycoprotein inhibitors [10].

\section{Conclusion}

The ACCP guidelines include recommendations on the use of rivaroxaban, dabigatran, and apixaban for the prevention of VTE after THA or TKA [20]. Clinical experience with these newer oral agents is relatively limited, especially for apixaban, but they appear to be well tolerated and easily managed in the clinic. Potential issues with their management, such as the effect of postoperative vomiting on efficacy, or the reversal of the anticoagulant effect in an emergency, can generally be managed with routine clinical procedures. The direct oral anticoagulants possess many advantages over the more established agents, including administration of the first dose postoperatively, no requirement for routine coagulation monitoring, and limited drug-drug interactions. Furthermore, the convenience of oral administration could improve patient compliance postdischarge, although, as with any anticoagulant that is self-administered, effective patient education in this area is crucial [9]. Clinical experience with rivaroxaban, dabigatran, and apixaban so far supports the potential of these drugs to improve and simplify routine management of VTE prevention postoperatively.

Acknowledgments The authors would like to acknowledge Sarah Atkinson, who provided editorial support with funding from Bayer HealthCare Pharmaceuticals and Janssen Scientific Affairs, LLC.

Conflict of interest One of the authors (W.K.) has received an honorarium for lecturing on oral anticoagulants from Bayer HealthCare Pharmaceuticals.

Open Access This article is distributed under the terms of the Creative Commons Attribution License which permits any use, distribution, and reproduction in any medium, provided the original author(s) and the source are credited.

\section{References}

1. Ageno W, Gallus AS, Wittkowsky A, Crowther M, Hylek EM, Palareti G (2012) Oral anticoagulant therapy: antithrombotic therapy and prevention of thrombosis, 9th ed: American College of Chest Physicians evidence-based clinical practice guidelines. Chest 141:e44S-e88S

2. Allen DJ, Chae-Kim SH, Trousdale DM (2002) Risks and complications of neuraxial anesthesia and the use of anticoagulation in the surgical patient. Proc (Bayl Univ Med Cent) 15:369-373

3. Ansell J, Hirsh J, Hylek E, Jacobson A, Crowther M, Palareti G (2010) Pharmacology and management of the vitamin K antagonists: American College of Chest Physicians evidence-based clinical practice guidelines (8th edition). Chest 133:160S-198S

4. Association of the Scientific Medical Societies in Germany (2010) S3-Leitlinie Prophylaxe der venösen Thromboembolie (VTE). Available at: http://www.awmf.org/uploads/tx_szleitlinien/ 003-0011_S3_Thromboembolie-Prophylaxe_2010.pdf. Accessed 12 Nov 2013

5. Baker RI, Coughlin PB, Gallus AS, Harper PL, Salem HH, Wood EM et al (2004) Warfarin reversal: consensus guidelines, on behalf of the Australasian Society of Thrombosis and Haemostasis. Med J Aust 181:492-497

6. Barrett YC, Wang Z, Frost C, Shenker A (2010) Clinical laboratory measurement of direct Factor Xa inhibitors: Anti-Xa assay is preferable to prothrombin time assay. Thromb Haemost 104:1263-1271

7. Bayer Pharma AG (2013) Xarelto ${ }^{\circledR}$ (rivaroxaban) summary of product characteristics. Available at: http://www.ema.europa.eu/ docs/en_GB/document_library/EPAR_-_Product_Information/ human/000944/WC500057108.pdf. Accessed 28 Feb 2013

8. Becker RC, Yang H, Barrett Y, Mohan P, Wang J, Wallentin L et al (2011) Chromogenic laboratory assays to measure the factor Xa-inhibiting properties of apixaban - an oral, direct and selective factor Xa inhibitor. J Thromb Thrombolysis 32:183-187

9. Bellamy L, Rosencher N, Eriksson B (2009) Adherence to a new oral anticoagulant treatment prescription: dabigatran etexilate. Patient Prefer Adherence 3:173-177

10. Boehringer Ingelheim International $\mathrm{GmbH}$ (2013) Pradaxa ${ }^{\circledR}$ (dabigatran etexilate) summary of product characteristics. Available at: http://www.ema.europa.eu/docs/en_GB/document_ library/EPAR_-_Product_Information/human/000829/WC50004 1059.pdf. Accessed 6 Mar 2013

11. Boersma C, Kappelhoff BS, Postma MJ (2009) Administration advantages and cost-savings with dabigatran etexilate versus 
parenteral agents for thromboprophylaxis after major orthopaedic surgery in the Netherlands. Blood 114:563

12. Bristol-Myers Squibb and Pfizer EEIG (2012) Eliquis ${ }^{\circledR}$ (apixaban) summary of product characteristics. Available at: http:// www.ema.europa.eu/docs/en_GB/document_library/EPAR_-_Product_Information/human/002148/WC500107728.pdf. Accessed 22 Feb 2013

13. Donat F, Duret JP, Santoni A, Cariou R, Necciari J, Magnani H et al (2002) The pharmacokinetics of fondaparinux sodium in healthy volunteers. Clin Pharmacokinet 41(Suppl 2):1-9

14. Eerenberg ES, Kamphuisen PW, Sijpkens MK, Meijers JC, Buller HR, Levi M (2011) Reversal of rivaroxaban and dabigatran by prothrombin complex concentrate: a randomized, placebo-controlled, crossover study in healthy subjects. Circulation 124:1573-1579

15. Eriksson B, Turpie AGG, Lassen MR, Kakkar AK, Misselwitz F, Bandel TJ et al (2008) A pooled analysis of four pivotal studies of rivaroxaban for the prevention of venous thromboembolism after orthopaedic surgery: effects of specified co-medications. Blood (ASH Annual Meeting Abstracts) 112. Abstract 1986

16. Eriksson BI, Borris LC, Friedman RJ, Haas S, Huisman MV, Kakkar AK et al (2008) Rivaroxaban versus enoxaparin for thromboprophylaxis after hip arthroplasty. N Engl J Med 358:2765-2775

17. Eriksson BI, Dahl OE, Rosencher N, Kurth AA, van Dijk CN, Frostick SP et al (2007) Oral dabigatran etexilate vs. subcutaneous enoxaparin for the prevention of venous thromboembolism after total knee replacement: the RE-MODEL randomized trial. J Thromb Haemost 5:2178-2185

18. Eriksson BI, Dahl OE, Rosencher N, Kurth AA, van Dijk CN, Frostick SP et al (2007) Dabigatran etexilate versus enoxaparin for prevention of venous thromboembolism after total hip replacement: a randomised, double-blind, non-inferiority trial. Lancet 370:949-956

19. Eriksson BI, Kurth AA, Friedman RJ, Schnee JM, Clemens A, Noack H et al (2009) Risk of bleeding with dabigatran etexilate in patients undergoing major orthopaedic surgery is not increased by concomitant use of non-steroidal anti-inflammatory drugs or acetylsalicylic acid. J Thromb Haemost 7:374. Abstract PP-MO167

20. Falck-Ytter Y, Francis CW, Johanson NA, Curley C, Dahl OE, Schulman S et al (2012) Prevention of VTE in orthopedic surgery patients: antithrombotic therapy and prevention of thrombosis, 9th ed: American College of Chest Physicians evidence-based clinical practice guidelines. Chest 141:e278S-e325S

21. Favaloro EJ, Lippi G (2012) The new oral anticoagulants and the future of haemostasis laboratory testing. Biochem Med (Zagreb) 22:329-341

22. Fischer HB, Simanski CJ (2005) A procedure-specific systematic review and consensus recommendations for analgesia after total hip replacement. Anaesthesia 60:1189-1202

23. Fischer HB, Simanski CJ, Sharp C, Bonnet F, Camu F, Neugebauer EA et al (2008) A procedure-specific systematic review and consensus recommendations for postoperative analgesia following total knee arthroplasty. Anaesthesia 63:1105-1123

24. Friedman RJ, Gallus AS, Cushner FD, Fitzgerald G, Anderson FA Jr, Global Orthopaedic Registry Investigators (2008) Physician compliance with guidelines for deep-vein thrombosis prevention in total hip and knee arthroplasty. Curr Med Res Opin 24:87-97

25. Frost C, Lee L, Li LY, Nepal S, Shenker A, Reeves RA (2007) Apixaban does not affect the pharmacokinetics of digoxin. J Clin Pharmacol 47. Abstract 60

26. Frost C, Yu Z, Moore K, Nepal S, Barrett R, Mosqueda-Garcia R et al (2007) Apixaban, an oral direct Factor Xa inhibitor: multiple-dose safety, pharmacokinetics, and pharmacodynamics in healthy subjects. J Thromb Haemost 5(Suppl 2). Abstract P-M664

27. Gan TJ (2006) Risk factors for postoperative nausea and vomiting. Anesth Analg 102:1884-1898

28. Garcia DA, Baglin TP, Weitz JI, Samama MM (2012) Parenteral anticoagulants: antithrombotic therapy and prevention of thrombosis, 9th ed: American College of Chest Physicians evidencebased clinical practice guidelines. Chest 141:e24S-e43S

29. Geerts WH, Bergqvist D, Pineo GF, Heit JA, Samama CM, Lassen MR et al (2008) Prevention of venous thromboembolism: American College of Chest Physicians evidence-based clinical practice guidelines (8th edition). Chest 133:381S-453S

30. Glassock RJ, Winearls C (2009) Ageing and the glomerular filtration rate: truths and consequences. Trans Am Clin Climatol Assoc 120:419-428

31. GlaxoSmithKline (2011) Arixtra (fondaparinux sodium) prescribing information. Available at: http://us.gsk.com/products/ assets/us_arixtra.pdf. Accessed 18 Oct 2012

32. Herkowitz HN, Dirschl DR, Sohn DH (2007) Pain management: the orthopaedic surgeon's perspective. J Bone Joint Surg Am 89:2532-2535

33. Hirsh J, Bauer KA, Donati MB, Gould M, Samama MM, Weitz JI (2008) Parenteral anticoagulants: American College of Chest Physicians evidence-based clinical practice guidelines (8th edition). Chest 133:141S-159S

34. Horlocker TT, Wedel DJ, Benzon H, Brown DL, Enneking FK, Heit JA et al (2003) Regional anesthesia in the anticoagulated patient: defining the risks (the second ASRA consensus conference on neuraxial anesthesia and anticoagulation). Reg Anesth Pain Med 28:172-197

35. Kakkar AK, Brenner B, Dahl OE, Eriksson BI, Mouret P, Muntz J et al (2008) Extended duration rivaroxaban versus short-term enoxaparin for the prevention of venous thromboembolism after total hip arthroplasty: a double-blind, randomised controlled trial. Lancet 372:31-39

36. Kubitza D, Becka M, Mueck W, Zuehlsdorf M (2006) Safety, tolerability, pharmacodynamics, and pharmacokinetics of rivaroxaban - an oral, direct Factor Xa inhibitor-are not affected by aspirin. J Clin Pharmacol 46:981-990

37. Kubitza D, Becka M, Mueck W, Zuehlsdorf M (2007) Coadministration of rivaroxaban-a novel, oral, direct Factor Xa inhibitor-and clopidogrel in healthy subjects. Eur Heart J 28(Suppl 1):189. Abstract P1272

38. Kubitza D, Becka M, Roth A, Mueck W (2008) Dose-escalation study of the pharmacokinetics and pharmacodynamics of rivaroxaban in healthy elderly subjects. Curr Med Res Opin 24:2757-2765

39. Kubitza D, Becka M, Voith B, Zuehlsdorf M, Wensing G (2005) Safety, pharmacodynamics, and pharmacokinetics of single doses of BAY 59-7939, an oral, direct Factor Xa inhibitor. Clin Pharmacol Ther 78:412-421

40. Kubitza D, Becka M, Wensing G, Voith B, Zuehlsdorf M (2005) Safety, pharmacodynamics, and pharmacokinetics of BAY 59-7939-an oral, direct Factor Xa inhibitor - after multiple dosing in healthy male subjects. Eur J Clin Pharmacol 61:873-880

41. Kubitza D, Becka M, Zuehlsdorf M, Mueck W (2006) Effect of food, an antacid, and the $\mathrm{H} 2$ antagonist ranitidine on the absorption of BAY 59-7939 (rivaroxaban), an oral, direct Factor Xa inhibitor, in healthy subjects. J Clin Pharmacol 46:549-558

42. Lassen MR, Ageno W, Borris LC, Lieberman JR, Rosencher N, Bandel TJ et al (2008) Rivaroxaban versus enoxaparin for thromboprophylaxis after total knee arthroplasty. N Engl J Med 358:2776-2786

43. Lassen MR, Raskob GE, Gallus A, Pineo G, Chen D, Portman RJ (2009) Apixaban or enoxaparin for thromboprophylaxis after knee replacement. N Engl J Med 361:594-604 
44. Lassen MR, Gallus A, Raskob GE, Pineo G, Chen D, Ramirez LM, ADVANCE-3 Investigators (2010) Apixaban versus enoxaparin for thromboprophylaxis after hip replacement. N Engl J Med 363:2487-2498

45. Lassen MR, Raskob GE, Gallus A, Pineo G, Chen D, Hornick P, ADVANCE-2 Investigators (2010) Apixaban versus enoxaparin for thromboprophylaxis after knee replacement (ADVANCE-2): a randomised double-blind trial. Lancet 375:807-815

46. Marlu R, Hodaj E, Paris A, Albaladejo P, Crackowski JL, Pernod G (2012) Effect of non-specific reversal agents on anticoagulant activity of dabigatran and rivaroxaban. A randomised crossover ex vivo study in healthy volunteers. Thromb Haemost 108:217-224

47. National Institute for Health and Clinical Excellence (2011) Dabigatran etexilate for the prevention of venous thromboembolism after hip or knee replacement surgery in adults. Technology appraisal guidance 157. Available at: http://www.nice. org.uk/nicemedia/pdf/TA157Guidance.pdf. Accessed 5 Mar 2013

48. National Institute for Health and Clinical Excellence (2012) Apixaban for the prevention of venous thromboembolism after total hip or knee replacement in adults. Available at: http://www. nice.org.uk/nicemedia/live/13648/57895/57895.pdf. Accessed 28 Feb 2013

49. National Institute for Health and Clinical Excellence (2012) Rivaroxaban for the prevention of venous thromboembolism after total hip or total knee replacement in adults. Technology appraisal guidance 170. Available at: http://www.nice.org.uk/ nicemedia/pdf/TA170Guidance.pdf. Accessed 4 Mar 2013

50. Quante M, Thate-Waschke IM (2009) Comparative research between oral and subcutaneous thromboprophylaxis: the stopwatch project. Value Health 12:A339

51. Raskob GE, Hirsh J (2003) Controversies in timing of the first dose of anticoagulant prophylaxis against venous thromboembolism after major orthopedic surgery. Chest 124:379S-385S

52. Roehrig S, Straub A, Pohlmann J, Lampe T, Pernerstorfer J, Schlemmer KH et al (2005) Discovery of the novel antithrombotic agent 5-chloro-N-([(5S)-2-oxo-3-[4-(3-oxomorpholin-4yl)phenyl]-1,3-oxazolidin-5-yl]methyl)thiophene-2-carboxamide (BAY 59-7939): an oral, direct factor Xa inhibitor. J Med Chem 48:5900-5908

53. Rosencher N, Bonnet MP, Sessler DI (2007) Selected new antithrombotic agents and neuraxial anaesthesia for major orthopaedic surgery: management strategies. Anaesthesia 62:1154-1160

54. Samama MM, Contant G, Spiro TE, Perzborn E, Flem LL, Guinet $C$ et al (2012) Evaluation of the prothrombin time for measuring rivaroxaban plasma concentrations using calibrators and controls: results of a multicenter field trial. Clin Appl Thromb Hemost 18:150-158

55. Samama MM, Contant G, Spiro TE, Perzborn E, Guinet C, Gourmelin Y et al (2012) Evaluation of the anti-Factor Xa chromogenic assay for the measurement of rivaroxaban plasma concentrations using calibrators and controls. Thromb Haemost 107:379-387

56. Samama MM, Martinoli JL, Le Flem L, Guinet C, Plu-Bureau G, Depasse F et al (2010) Assessment of laboratory assays to measure rivaroxaban-an oral, direct Factor Xa inhibitor. Thromb Haemost 103:815-825

57. Scottish Medicines Consortium (2008) Scottish Medicines Consortium dabigatran VTE prevention guidelines. Available at: http://www.scottishmedicines.org.uk/files/dabigatran_etexilate_ Pradaxa_FINAL_May_2008_for_website.pdf. Accessed 7 Sep 2011

58. Scottish Medicines Consortium (2008) Scottish Medicines Consortium rivaroxaban VTE prevention guidelines. Available at: http://www.scottishmedicines.org.uk/files/rivaroxaban_10mg_film_ coated_tablets_Xarelto_FINAL_NOVEMBER_2008.doc_amend ed_021208.doc_for_website.pdf. Accessed 7 Sep 2011

59. Scottish Medicines Consortium (2011) Scottish Medicines Consortium apixaban VTE prevention guidelines. Available at: http://www.scottishmedicines.org.uk/files/advice/apixaban_Eliquis_ FINAL_November_2011_for_website.pdf. Accessed 28 Feb 2013

60. Smith SA, Morrissey JH (2007) Thromboplastin composition affects the sensitivity of prothrombin time (PT) clotting tests to direct Factor Xa inhibitors. Blood (ASH Annual Meeting Abstracts) 110. Abstract 928

61. Stangier J, Eriksson BI, Dahl OE, Ahnfelt L, Nehmiz G, Stahle H et al (2005) Pharmacokinetic profile of the oral direct thrombin inhibitor dabigatran etexilate in healthy volunteers and patients undergoing total hip replacement. J Clin Pharmacol 45:555-563

62. Stangier J, Feuring M (2012) Using the HEMOCLOT direct thrombin inhibitor assay to determine plasma concentrations of dabigatran. Blood Coagul Fibrinolysis 23:138-143

63. Stangier J, Rathgen K, Stahle H, Gansser D, Roth W (2007) The pharmacokinetics, pharmacodynamics and tolerability of dabigatran etexilate, a new oral direct thrombin inhibitor, in healthy male subjects. Br J Clin Pharmacol 64:292-303

64. Stangier J, Stähle H, Rathgen K, Fuhr R (2008) Pharmacokinetics and pharmacodynamics of the direct oral thrombin inhibitor dabigatran in healthy elderly subjects. Clin Pharmacokinet 47:47-59

65. The RE-MOBILIZE Writing Committee (2009) Oral thrombin inhibitor dabigatran etexilate vs North American enoxaparin regimen for prevention of venous thromboembolism after knee arthroplasty surgery. J Arthroplast 24:1-9

66. Turpie AGG, Gallus AS, Hoek JA, Pentasaccharide Investigators (2001) A synthetic pentasaccharide for the prevention of deepvein thrombosis after total hip replacement. $\mathrm{N}$ Engl J Med 344:619-625

67. Turpie AGG, Lassen MR, Davidson BL, Bauer KA, Gent M, Kwong LM et al (2009) Rivaroxaban versus enoxaparin for thromboprophylaxis after total knee arthroplasty (RECORD4): a randomised trial. Lancet 373:1673-1680

68. Wang L, Zhang D, Raghavan N, Yao M, Ma L, Frost CE et al (2010) In vitro assessment of metabolic drug-drug interaction potential of apixaban through cytochrome P450 phenotyping, inhibition, and induction studies. Drug Metab Dispos 38:448-458

69. Wong PC, Pinto DJ, Zhang D (2011) Preclinical discovery of apixaban, a direct and orally bioavailable Factor Xa inhibitor. J Thromb Thrombolysis 31:478-492 